\title{
Simultaneous optimal allocation and sizing of distributed generations and shunt capacitors in distribution networks using fuzzy GA methodology
}

\author{
Srinivasa Rao Gampa ${ }^{1^{*}}$ (D) and Debapriya Das ${ }^{2}$
}

${ }^{*}$ Correspondence:

gsr_gsrinu@yahoo.co.in

${ }^{1}$ Department of Electrical

and Electronics Engineering

Gudlavalleru Engineering

College, Gudlavalleru, Andhra

Pradesh 521356, India

Full list of author information

is available at the end of the

article

\begin{abstract}
This paper presents a combination of fuzzy and genetic algorithm (GA)-based methodology for simultaneous optimum allocation and sizing of distributed generations (DGs) and shunt capacitors (SCs) together in distribution systems. The objectives of reduction of active power and reactive power supply, reduction of real power loss and improvement of branch current capacity, voltage profile and voltage stability are considered. The combination of shunt capacitors with both unity power factor DGs and lagging power factor DGs also considered for analyzing the performance of the distribution systems. Simulation results are demonstrated to show the advantage of proposed fuzzy genetic algorithm-based technique over conventional multiobjective approach and loss sensitivity-based optimization techniques reported in the literature.
\end{abstract}

Keywords: Distributed generations, Sensitivity analysis, Simultaneous optimization technique, Voltage stability index, Fuzzy GA method

\section{Introduction}

The distributed generation (DG) mainly depends on the renewable energy sources such as wind power, photovoltaic, solar thermal systems and biomass, and in small scale also considers energy sources such as combined heat and power (CHP), gas turbine and diesel generators. Placement of DG at inappropriate locations results in greater power losses and causes magnitude reduction in voltage profile. Hence the selection of optimum location and size of DG is essential for minimizing power losses and improving voltage profile before it is integrated to distribution system. It is traditional practice of power engineers to incorporate shunt capacitors (SCs) for reactive power compensation in distribution system for better voltage profile of the distribution system.

For the past few years many researchers have proposed various techniques for finding optimum location and size of the DGs and recently some of the researchers also developed techniques for simultaneously incorporating DGs and shunt capacitors together for compensation both real and reactive power in distribution systems. Khattam and Salama [1] have presented the role of DGs, their types, available technologies, operational constraints, economical and technical benefits in implementing DGs in modern power systems. Ganguly et al. [2] have proposed novel

(c) The Author(s) 2019. This article is distributed under the terms of the Creative Commons Attribution 4.0 International License (http://creativecommons.org/licenses/by/4.0/), which permits unrestricted use, distribution, and reproduction in any medium, provided you give appropriate credit to the original author(s) and the source, provide a link to the Creative Commons license, and indicate if changes were made. 
multiobjective-based PSO approach for distribution system planning considering distributed generations considering the objectives of optimal DG penetration levels. Szuvovivski et al. [3] proposed optimum placement of capacitors and voltage regulators simultaneously using GA and optimal power flow with optimum financial investment. Kalantari and Kazemi [4] have proposed genetic algorithm-based conventional multiobjective function for voltage profile improvement and loss reduction in distribution systems. Griffin et al. [5] have presented loss sensitivity analysis-based simple heuristic technique for optimal allocation of DG units for power loss minimization. Recently some research groups [6-9] have proposed simultaneous allocation of DGs and shunt capacitors considering the objective of reducing real power loss. Gampa and Das [10] proposed genetic algorithm-based technique for optimum placement of DGs in distribution systems considering the objectives of both technical and economical factors. Zeinalzadeh et al. [11] have presented a pareto multiobjective PSO algorithm for finding the optimal location and sizing of DGs and shunt capacitors by modeling load uncertainties using fuzzy logic. Kanwar et al. [12] have proposed improved meta-heuristic techniques for simultaneous placement of DGs and shunt capacitors in radial distribution systems for obtaining maximum annual energy loss reduction and improving system node voltage profile under multi-load level conditions. Khan et al. [13] have proposed binary collective animal behavior algorithm for solving simultaneous optimum sizing and allotment of DGs and Capacitors in radial distribution systems for minimizing total line loss and total voltage deviation. Gampa and Das [14] proposed fuzzy GA methodology for shunt capacitors optimum allocation in radial distribution systems for improving the power factor of the substation. Tah and Das [15] proposed a novel analytical method independent of bus impedance matrix for obtaining optimum DG sizing at every bus considering the objective of minimizing real power loss. They introduced $\mathrm{P}$ and PQV buses in the load flow and developed expressions for optimum DG units sizing of in the presence of $\mathrm{P}$ and PQV buses. Ghaffarzadeh and Sadeghi [16] proposed and efficient biogeography-based optimization (BBO)-based algorithm for placement of shunt capacitors and inverterbased DGs considering the objective of reduction of total harmonic distortion in addition to reducing active and reactive power loss and improving the voltage profile. Khodabakhshian and Andishgar [17] developed a novel evolutionary algorithm called intersect mutation differential evolution (IMDE) for simultaneously allocating and sizing of DGs and shunt capacitors considering the objectives of minimizing the real power loss and loss expenses and satisfying voltage and current constraints. Rahmani-andebili [18] proposed a genetic algorithm-based optimization technique for sizing of DGs and shunt capacitors simultaneously considering the objective of minimizing the total cost for purchase and maintenance of DGs and shunt capacitors. Kayal and Chanda [19] have proposed non-dominated sorting-based multiobjective PSO optimization technique with fuzzy decision criteria for the determination of optimum allocation of renewable energy sources and shunt capacitors. Rahiminejad et al. [20] proposed a modified teaching learning-based optimization technique for simultaneous placement of distributed generations (DGs), capacitors, and reconfiguration of distribution systems to minimize real power loss and maximize reliability of distribution network. Kanwar et al. [21] have proposed an improved PSO technique 
for simultaneous placement of distributed energy resources in radial distribution systems with the objectives of maximum annual savings and improving node voltage feeder current profiles.

Earlier distributed generators are limited to operate at unity power factor to avoid interference with voltage regulation devices and hence the combination of upf DGs and shunt capacitors are used to meet the requirements of real and reactive power of the distribution systems. The doubly fed induction generator-based wind generators and solar photo voltaic inverter systems can operate at lagging power factor and can supply both real and reactive power. Hence it is necessary to find the effect of combination of lagging power factor DGs and shunt capacitors on shunt capacitor sizing and distribution system performance compared with the combination of upf DGs and shunt capacitors [14]. In this paper fuzzy GAbased simultaneous optimization technique for the placement of DGs and shunt capacitors together is proposed. In general the selection of location for DG placement in a distribution system depends on urbanity and environmental conditions [14]. The optimal selection of DGs can be done either by ranking the nodes using voltage and loss sensitivity-based approaches or simultaneous optimal allocation-based approaches [4-18] and it is necessary to compare the effect of selection of nodes on the performance of the distribution system using both the methods.

\section{Methods}

In this paper fuzzy GA-based methodology has been developed for simultaneous optimum sizing and placement of DGs and shunt capacitors. The loss sensitivity generally aims at finding optimal locations to obtain the maximum possible reduction of real power losses of the distribution system. The effect of optimal allocation of DG units and shunt capacitors on distribution system performance using sensitivity analysis-based ranking system and simultaneous optimization techniques are compared in the present work.

In "Sensitivity analysis" section the sensitivity analysis method [22] for optimum allocation of DGs and SCs is discussed. The procedure for calculating optimum nodes is demonstrated with two examples. In "Multiobjective function formulation in fuzzy domain" section the objectives designed for performance improvement of distribution system by the optimum placement of DGs and SCs is presented. The fuzzification and design of fuzzy membership functions for the objectives is discussed in detail. In "Simultaneous optimum selection of nodes and optimum sizing of DGs and shunt capacitors by using fuzzy GA approach" section the proposed fuzzy GA methodology is discussed in detail for simultaneous placement of optimum DGs and SCs. In "Results and discussions" section the simulations results are demonstrated and analyzed with two examples. The simulation results are also compared with conventional GA-based multiobjective approach [4] and loss sensitivity-based techniques [9] available in the literature to project the advantage of the proposed fuzzy GA-based simultaneous optimization technique.

\section{Sensitivity analysis}

A simple sensitivity index [22] combining loss and voltage sensitivities is described by Eq. (1) is used for identifying the best nodes for incorporating DG units and shunt capacitors in the distribution network. 
Table 1 Load flow results without DGs and shunt capacitors

\begin{tabular}{lllllll}
\hline $\begin{array}{l}\text { Network } \\
\text { considered }\end{array}$ & $\begin{array}{l}\text { S/S active } \\
\text { power }(\mathbf{k W})\end{array}$ & $\begin{array}{l}\text { S/S reactive } \\
\text { power (kVAR) }\end{array}$ & $\begin{array}{l}\text { Active } \\
\text { power loss } \\
(\mathbf{k W})\end{array}$ & $\begin{array}{l}\text { Reactive } \\
\text { power loss } \\
(\mathbf{k V A r})\end{array}$ & $\boldsymbol{V}_{\min }(\mathbf{p u})$ & Sensitivity index \\
\hline 51 bus & 2592.56 & 1680.68 & 129.56 & 111.68 & $0.9081\left(V_{\min }^{16}\right)$ & $u=0.0480$ \\
69 bus & 4027.19 & 2796.77 & 225.00 & 102.17 & $0.9092\left(V_{\min }^{65}\right)$ & $u=0.0913$ \\
\hline
\end{tabular}

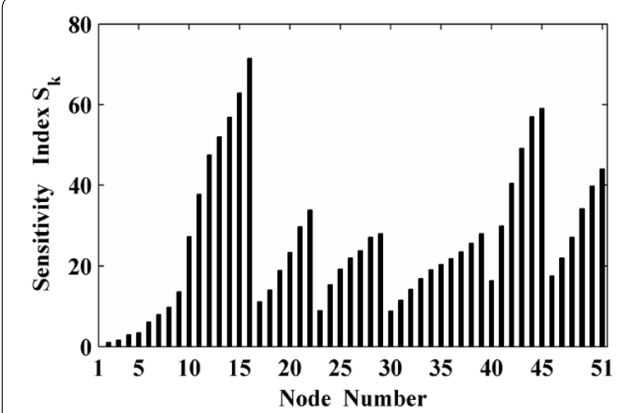

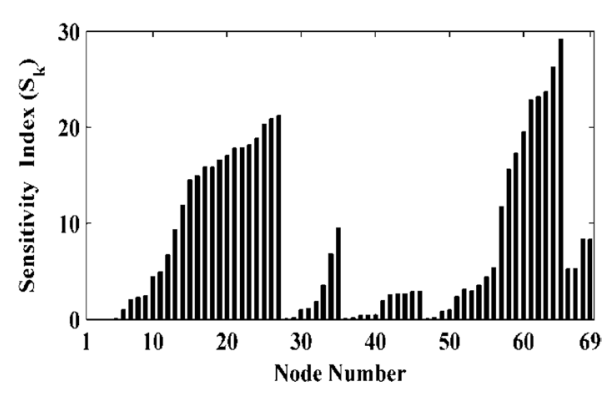

b

Fig. 1 a Sensitivity index $S_{k}$ with active DG power injection of 20\% of total active load. b Sensitivity index $S_{k}$ with active DG power injection of 69-node network

$$
S_{k}=\frac{\Delta V_{k}^{\max }}{\text { Ploss }_{k}}
$$

where

$$
\Delta V_{k}^{\max }=\max \left(\left|\tilde{V}_{m, k}^{\mathrm{DG} / \mathrm{SC}}\right|-\left|\tilde{V}_{m, k}^{\text {base }}\right|\right), \quad \text { for } m=2,3,4,5, \ldots, \mathrm{NB} .
$$

For DG placement considering from node two onwards at every node active power and for capacitor placement reactive power is injected and the sensitivity indices are calculated from Eq. (1). The nodes will have maximum sensitivity indices with minimum power loss and maximum improvement in voltage magnitude. For the present analysis $11 \mathrm{kV}$, 51-node radial distribution system [10] and a $12.66 \mathrm{kV}, 69$-node [23] radial distribution networks are considered. The active power and reactive power supplied by the substation, active and reactive power losses of the network and the minimum voltage values for the two cases, 51-node and 69-node distribution systems are shown in Table 1.

The order of ranking of the distribution system nodes can be obtained by the sensitivity index $S_{k}$ described by Eq. (1) for the placement of DGs and shunt capacitors. At each node $20 \%$ of total real power load and $20 \%$ of total reactive power load is injected independently and from Eq. (1) value of $S_{k}$ is computed. The bar graphs of the sensitivity index $\left(S_{k}\right)$ at each node for the placement of DGs for 51-node and 69-node distribution are shown in Fig. 1a, b, respectively.

The order of ranking of nodes is given according by descending order of $S_{k}$ and the ranking of nodes for both 51- and 69-node distribution systems for the placement of DGs and shunt capacitors are presented in Table 2. 
Table 2 Ranking of nodes using sensitivity analysis

\begin{tabular}{|c|c|c|c|c|}
\hline \multirow{2}{*}{$\begin{array}{l}\text { Order of the ranking } \\
\text { of nodes }\end{array}$} & \multicolumn{2}{|c|}{ 51-node distribution system } & \multicolumn{2}{|c|}{ 69-node distribution system } \\
\hline & $\begin{array}{l}\text { Nodes for DG } \\
\text { injection }\end{array}$ & $\begin{array}{l}\text { Nodes for QC } \\
\text { injection }\end{array}$ & $\begin{array}{l}\text { Nodes for DG } \\
\text { injection }\end{array}$ & $\begin{array}{l}\text { Nodes } \\
\text { for QC } \\
\text { injection }\end{array}$ \\
\hline 1 & 16 & 16 & 65 & 65 \\
\hline 2 & 15 & 15 & 64 & 64 \\
\hline 3 & 45 & 14 & 63 & 63 \\
\hline
\end{tabular}

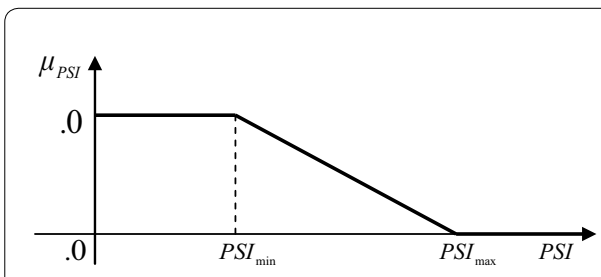

a

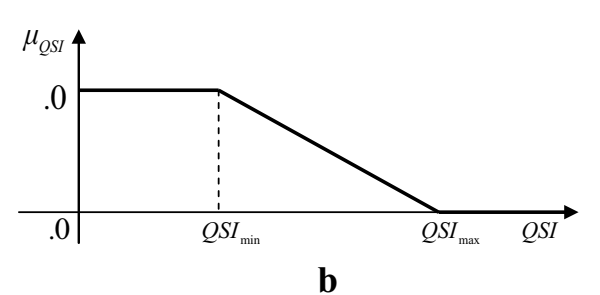

b

Fig. 2 a Membership function for S/S real power supply. b Membership function for $S / S$ reactive power supply

\section{Multiobjective function formulation in fuzzy domain}

Fuzzy logic is an extrapolation of classical set theory which provides mathematical framework for processing uncertainty in the information available by assigning membership values from zero to one [24]. In this section the incommensurable conventional objectives are fuzzified to form a single objective function.

\section{Fuzzification of $S / S$ real power supply index}

The S/S real power supply index is defined as the ratio of real power supply by the substation considering with DGs and shunt capacitors and without considering DGs and shunt capacitors placement.

Let us define,

$$
\text { SPSI }=\frac{\text { SPS }^{\text {DGSC }}}{\text { SPS }^{\text {Base }}}
$$

The fuzzification of S/S real power supply index (SPSI) is carried out considering the trapezoidal fuzzy set ( $\left.\mu_{\text {SPSI }}\right)$ shown in Fig. 2a. The membership value of unity is given by the fuzzy set if the substation real power supply is limited to $40 \%$ of base case substation active power value and below by the DGs and shunt capacitors otherwise the value will be below unity. The mathematical expression for the fuzzy set can be derived from the fuzzy set shown in Fig. 2a. From Fig. 2a, $\mu_{\text {SPSI }}$ can be described mathematically using Eq. (4):

$$
\mu_{\text {SPSI }}= \begin{cases}1 & \text { for SPSI } \leq \mathrm{SPSI}_{\min } \\ \frac{\left(\mathrm{SPSI}_{\max }-\mathrm{SPSI}\right)}{\text { (SPSI } \left._{\max }-\mathrm{SPSI}_{\min }\right)} & \text { for SPSI } \min <\mathrm{SPSI}_{0} \leq \mathrm{SPSI}_{\max } \\ 0 & \text { for SPSI }>\mathrm{SPSI}_{\max }\end{cases}
$$


In this work $\mathrm{SPSI}_{\min }$ and $\mathrm{SPSI}_{\max }$ are taken as 0.4 and 1.0 , respectively.

\section{Fuzzification of $S / S$ reactive power supply index}

The $\mathrm{S} / \mathrm{S}$ reactive power supply index is defined as the ratio of real power supply by the substation considering with DGs and shunt capacitors and without considering DGs and shunt capacitors placement.

Let us define,

$$
\text { SQSI }=\frac{\text { SQS }^{\text {DGSC }}}{\text { SQS }^{\text {Base }}}
$$

The fuzzification of S/S reactive power supply index (SQSI) is carried out considering the trapezoidal fuzzy set $\left(\mu_{\mathrm{SQSI}}\right)$ shown in Fig. $2 \mathrm{~b}$. The membership value of unity is given by the fuzzy set if the substation reactive power supply is limited to $40 \%$ of base case substation reactive power value and below by the DGs and shunt capacitors otherwise the value will be below unity. The mathematical expression for the fuzzy set can be derived from the fuzzy set shown in Fig. 2b. From Fig. 2b, $\mu_{\mathrm{SQSI}}$ can be described mathematically using Eq. (6):

$$
\mu_{\mathrm{SQSI}}= \begin{cases}1 & \text { for } \mathrm{SQSI} \leq \mathrm{SQSI}_{\min } \\ \frac{\left(\mathrm{SQSI}_{\max }-\mathrm{SQSI}\right)}{\left(\mathrm{SQSI}_{\max }-\mathrm{SQSI}_{\min }\right)} & \text { for } \mathrm{SQSI} \text { min }<\mathrm{SQSI} \leq \mathrm{SQSI}_{\max } \\ 0 & \text { for } \mathrm{SQSI}>\mathrm{SQSI}_{\max }\end{cases}
$$

In this work SPSI $_{\min }$ and SPSImax are taken as 0.4 and 1.0, respectively.

\section{Fuzzified active power loss index}

The active power loss index is determined as the ratio of power loss with DG and shunt capacitors placement and without DG and shunt capacitors placement.

Let us define,

$$
\text { PLI }=\frac{\text { Ploss }^{\text {DG }}}{\text { Ploss }^{\text {Base }}} \text {. }
$$

The conventional loss index (PLI) is fuzzified and the trapezoidal fuzzy set considered for active power loss $\left(\mu_{\mathrm{PLI}}\right)$ is shown in Fig. 3a. In the fuzzy set a membership value of unity is assigned if the loss is reduced to below $40 \%$ by the installation of DGs and shunt

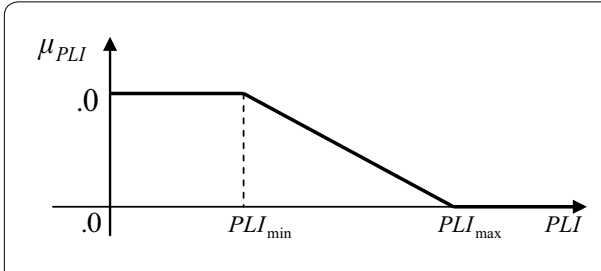

$\mathbf{a}$

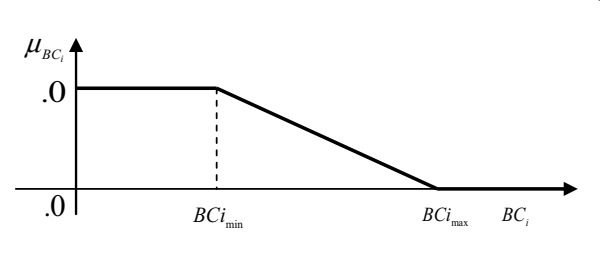

b

Fig. 3 a Membership function for active power loss reduction. b Membership function for branch current capacity 
capacitors and if the loss is greater than $40 \%$ then the membership value between zero to one is given. From Fig. 3a, $\mu_{\text {PLI }}$ can be described mathematically using Eq. (8):

$$
\mu_{\mathrm{PLI}}= \begin{cases}1 & \text { for } \mathrm{PLI} \leq \mathrm{PLI}_{\min } \\ \frac{\left(\mathrm{PLI}_{\max }-\mathrm{PLI}\right)}{\left(\mathrm{PLI}_{\max }-\mathrm{PLI}_{\min }\right)} & \text { for } \mathrm{PLI} \min <\mathrm{PLI} \leq \mathrm{PLI}_{\max } \\ 0 & \text { for PLI }>\mathrm{PLI}_{\max }\end{cases}
$$

In this work PLI $I_{\min }$ and PLI $\max$ are taken as 0.4 and 1.0, respectively.

\section{Fuzzified branch conductor current carrying ability limit index}

The branch current carrying capacity limit is defined as the ratio of branch current to its current carrying capacity.

Let us define,

Now we define branch current capacity ratio as:

$$
\mathrm{BCI}_{i}=\frac{I_{i}}{\mathrm{IC}_{i}}, \quad \text { for } i=1,2,3, \ldots, \mathrm{NB}-1 .
$$

The fuzzification of branch current carrying ability index $\left(B C I_{i}\right)$ of individual branches of the distribution system can be determined using trapezoidal shape membership function considered $\left(\mu_{\mathrm{BCI}_{i}}\right)$ is shown in Fig. 3b. From Fig. 3b, $\mu_{\mathrm{BCI}_{i}}$ can be written as:

$$
\mu_{\mathrm{BCI}_{i}}= \begin{cases}1 & \text { for } \mathrm{BCI}_{i} \leq \mathrm{BCI}_{\min } \\ \frac{\left(\mathrm{BCI}_{\max }-\mathrm{BCI}\right)}{\left(\mathrm{BCI}_{\max }-\mathrm{BCI}_{\min }\right)} & \text { for } \mathrm{BCI}_{\min }<\mathrm{BCI}_{i} \leq \mathrm{BCI}_{\max } \\ 0 & \text { for } \mathrm{BCI}_{i}>\mathrm{BCI}_{\max }\end{cases}
$$

The unity membership value is assigned if $B C I_{i}$ has a value less than 0.4 and the membership value will be within zero to one if the $B C I_{i}$ value is greater than 0.4 and hence in this work $\mathrm{BCI}_{\min }$ and $\mathrm{BCImax}$ are taken as 0.4 and 1.0, respectively.

In the present work, the average fuzzy membership functions of all the individual branch current capacity indices are considered as the fuzzified branch current capacity index of the distribution system.

Now we define fuzzy branch current capacity index of the distribution system as:

$$
\mu_{\mathrm{BCIT}}=\frac{1}{\mathrm{NB}-1} \sum_{i=1}^{\mathrm{NB}-1} \mu_{B C I_{i}} .
$$

\section{Fuzzified min and max voltage limits at distribution system nodes}

It is considered in this work that due to placement of DGs and shunt capacitors the node voltages of the distribution system must lie in within the specified voltage limits.

The following trapezoidal membership function is considered for fuzzified voltage limits.

\section{Fuzzification of voltage limits on node voltages}

The fuzzy membership functions of all the individual node voltages are determined using the fuzzy set shown in Fig. $4\left(\mu_{V_{i}}\right)$. 


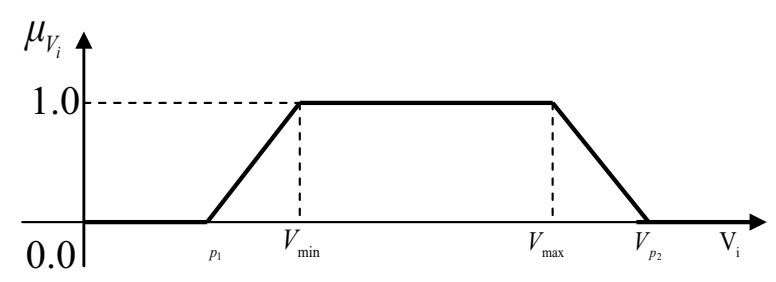

Fig. 4 Membership function for node voltage

If the distribution system voltage is less than a specified voltage $V_{\min }$ or greater than $V_{\max }$, then membership value of less than unity is assigned. If it lies in between $V_{\min }$ and $V_{\max }$, unity membership value is assigned.

From Fig. 4, we can write,

$$
\mu_{V_{i}}= \begin{cases}0 & \text { for } V_{i} \leq V_{p_{1}} \\ \frac{\left(V_{i}-V_{p_{1}}\right)}{\left(V_{\min }-V_{p_{1}}\right)} & \text { for } V_{p_{1}}<V_{i}<V_{\min } \\ 1.0 & \text { for } V_{\min } \leq V_{i} \leq V_{\max } \\ \frac{\left(V_{\max }-V_{i}\right)}{\left(V_{\max }-V_{p_{2}}\right)} & \text { for } V_{\max }<V_{i}<V_{p_{2}} \\ 0 & \text { for } V_{i}>V_{p_{2}}\end{cases}
$$

In this work, $V_{p_{1}}=0.93, V_{\min }=0.95, V_{\max }=1.05$ and $V_{p_{2}}=1.07$ are considered.

In the present work the average fuzzy membership functions of all the individual node voltages is considered as the fuzzy performance index of the distribution system.

Now we define fuzzy voltage limit of the distribution system as:

$$
\mu_{V T}=\frac{1}{\mathrm{NB}-1} \sum_{i=2}^{N B} \mu_{V_{I}} .
$$

\section{Fuzzified voltage stability index of distribution system nodes}

A voltage stability index [23] is used and is described by Eq. (14). The Voltage stability index of node ' $n$ ' of distribution system is given by

$$
\mathrm{SI}_{n}=\frac{4\left\{\left(P_{n} x_{\mathrm{mn}}-Q_{n} r_{\mathrm{mn}}\right)^{2}+\left(P_{n} r_{\mathrm{mn}}+Q_{n} x_{\mathrm{mn}}\right) V_{m}^{2}\right\}}{V_{m}^{4}}
$$

where ' $m$ ' is the sending end node and ' $n$ ' is the receiving end node, and,

$$
S I_{n} \leq 1 .
$$

Node at which $\mathrm{SI}_{n}(n=2,3, \ldots \ldots ., \mathrm{NB})$ is maximum, that node is most sensitive to voltage collapse. Therefore, voltage stability index of distribution network is given as:

$$
u=\max \left(\mathrm{SI}_{n}\right), \quad \text { for } n=2,3, \ldots, \mathrm{NB} .
$$

Figure 5 shows the fuzzy membership function for maximum $n$ voltage stability index $\left(\mu_{u}\right)$. If the value of ' $u$ ' is less than a specified value $u_{\mathrm{min}}$, unity membership value is assigned and if ' $u$ ' is greater than or equal to $u_{\max }$, membership value of zero is assigned. If ' $u$ ' is lying in between $u_{\min }$ and $u_{\max }$ membership value less than one is assigned. 


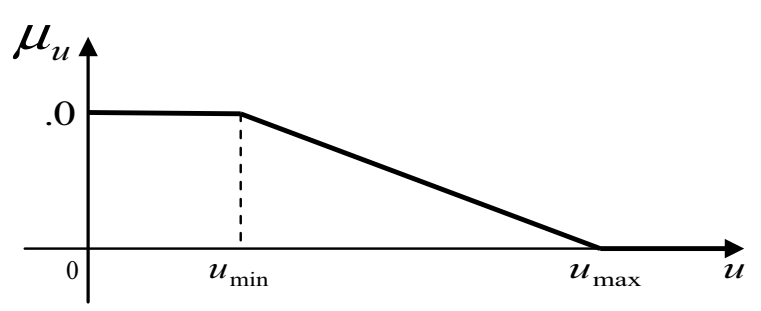

Fig. 5 Membership function for voltage stability index

From Fig. 5, we can write,

$$
\mu_{u}= \begin{cases}1 & \text { for } u \leq u_{\min } \\ \frac{\left(u_{\max }-u\right)}{\left(u_{\max }-u_{\min }\right)} & \text { for } u_{\min }<u \leq u_{\max } \\ 0 & \text { for } u>u_{\max }\end{cases}
$$

In this work $u_{\min }=0.04$, and $u_{\max }=1.0$ are considered.

Since the fuzzified objectives are developed from normalized conventional objectives all the fuzzy objectives can be added to unique objective function through weighting factors.

$$
F=w_{1} \mu_{\mathrm{SPSI}}+w_{2} \mu_{\mathrm{SQSI}}+w_{3} \mu_{\mathrm{PLI}}+w_{4} \mu_{\mathrm{BCIT}}+w_{5} \mu_{\mathrm{VT}}+w_{6} \mu_{u}
$$

Equal importance is considered for all the fuzzy objectives in Eq. (18) and the unity magnitude is taken for the weighting factors $W_{1}, W_{2}, W_{3}, W_{4}, W_{5}$, and $W_{6}$. However weighting factors can be varied according to the preferences of different operations. The fuzzy multiobjective function Eq. (18) is maximized subject to various operational constraints to satisfy the technical requirements of the distribution system for obtaining optimum DG capacity and shunt capacitor units. The authors have considered equal importance for all the fuzzy objectives and since the scaling of the fuzzy multiobjective function described by Eq. 18 does not effect the final optimization results, all the weighting factors of the objective function are considered unity magnitude value.

\section{Simultaneous optimum selection of nodes and optimum sizing of DGs and shunt capacitors by using fuzzy GA approach}

The fuzzified multiobjective expression given by Eq. (18) is taken as fitness function in GA [25]. In the present work the objectives of $S / S$ real power supply reduction, $S / S$ reactive power supply reduction, the real power loss reduction, branch current capacity and voltage profile improvements are considered for improving the performance of the distribution network with the placement of DGs and shunt capacitors. In the present work the optimal allocation of DGs and shunt capacitors and using both sensitivity analysis-based node ranking system and simultaneous allocation-based on fuzzy GA methodology are compared. In both the methodologies the following three cases are taken into consideration for the analysis.

Case 1 Optimal placement of upf DGs and shunt capacitors: In this case the DGs can only inject active power and reactive power is injected by shunt capacitors into the distribution system. 
Case 2 Optimal placement of 0.95 lag pf DGs only: in this case both the active power and reactive power are injected by the DGs operating at 0.95 power factor.

Case 3 Optimal placement of 0.95 lag pf DGs and shunt capacitors: in this the DGs will operate at $0.95 \mathrm{lag} \mathrm{pf}$ and can inject both active power and reactive power into the distribution system. The shunt capacitors are installed to compensate the additional reactive power required to meet the objectives considered.

Sensitivity analysis methodology for optimal placement of DGs and shunt capacitors

In the sensitivity analysis-based methodology initially the optimal locations of DGs and shunt capacitors are obtained using a combination of voltage and loss sensitivity. At the optimal locations obtained the optimum sizing of DGs are obtained using fuzzy GA methodology.

\section{Simultaneous placement of optimal DGs and shunt capacitors}

In the simultaneous optimization methodology, the problem of optimal locations and sizing of DGs and shunt capacitors is handled simultaneously proceeding in the direction of optimizing fuzzy multiobjective function using genetic algorithm.

\section{Fuzzy GA algorithm for simultaneous optimum placement of DGs and shunt capacitors}

The fuzzy GA-based algorithm for optimization of simultaneous optimization of DG units and shunt capacitors is explained as follows:

Step-1 Read the distribution system data.

Step-2 Generate binary strings and initialize the population for optimum sizing of DG units and shunt capacitors and for optimum locations of DG units and shunt capacitors.

Step-3 Set Gen $=1$.

Step-4 Evaluate the fitness function by computing the fuzzy multiobjective function (F) value of each member of the population and store the solution corresponding to the maximum value of the ' $\mathrm{F}$ ' in the population.

Step-5 Apply selection, crossover and mutation operations and generate the binary strings for new population from previous generation population.

Step-6 Apply elitism and incorporate the best fitness solution string of the previous generation population in the newly generated population.

Step-7 Set Gen $=$ Gen +1 .

Step-8 If Gen $\leq$ Gen Max goto Step-4.

Step-9 Store the optimum values of DG units and shunt capacitors.

\section{Results and discussion}

In this work, placement of optimum DGs and SCs using both sensitivity analysis method and simultaneous optimization method are analyzed. The performance of the distribution system with the incorporation of upf DG units and shunt capacitors, 0.95 lag pf DG units and combination of 0.95 lag pf DG units with shunt capacitors is considered.

The optimum sizing of DGs and shunt capacitors for the three cases considered is shown in Table 3 for 51-bus system and in Table 4 for 69-bus system for both sensitivity analysis and simultaneous optimization method. 
Table 3 Optimum sizing of DGs and shunt capacitors for 51-bus system

\begin{tabular}{|c|c|c|c|c|c|}
\hline \multicolumn{3}{|c|}{ Sensitivity analysis [22] } & \multicolumn{3}{|c|}{ Simultaneous optimization-based method } \\
\hline $\begin{array}{l}\text { With upf DGs } \\
\text { and shunt } \\
\text { capacitors }\end{array}$ & $\begin{array}{l}\text { With } 0.95 \text { lag pf } \\
\text { DGs Only }\end{array}$ & $\begin{array}{l}\text { With } 0.95 \text { lag pf } \\
\text { DGs and shunt } \\
\text { capacitors }\end{array}$ & $\begin{array}{l}\text { With upf DGs } \\
\text { and shunt } \\
\text { capacitors }\end{array}$ & $\begin{array}{l}\text { With } 0.95 \text { lag pf } \\
\text { DGs only }\end{array}$ & $\begin{array}{l}\text { With } 0.95 \text { lag pf } \\
\text { DGs and shunt } \\
\text { capacitors }\end{array}$ \\
\hline$P_{D G_{16}}=206.45$ & $\begin{array}{l}P_{D_{16}}=206.45 \\
Q_{D G_{16}}=67.86\end{array}$ & $\begin{array}{l}\mathrm{P}_{\mathrm{DG}_{16}}=189.09 \\
\mathrm{QDG}_{16}=62.15\end{array}$ & $P_{D G_{11}}=488.14$ & $\begin{array}{l}\mathrm{PDG}_{14}=492.00 \\
\mathrm{QDG}_{14}=161.72\end{array}$ & $\begin{array}{l}P_{D_{G}}=490.67 \\
Q_{D G_{6}}=161.28\end{array}$ \\
\hline$P_{D_{15}}=486.21$ & $\begin{array}{l}P_{D_{15}}=486.21 \\
Q_{D G_{15}}=159.82\end{array}$ & $\begin{array}{l}\mathrm{P}_{\mathrm{DG}_{15}}=490.07 \\
\mathrm{Q}_{\mathrm{DG}_{15}}=161.09\end{array}$ & $P_{D G_{41}}=490.07$ & $\begin{array}{l}P_{D G_{48}}=482.35 \\
Q_{D G_{48}}=158.55\end{array}$ & $\begin{array}{l}P_{D_{G 44}}=488.74 \\
Q_{D G_{44}}=160.65\end{array}$ \\
\hline$P_{D_{4} 5}=492.0$ & $\begin{array}{l}P_{D_{G_{45}}}=492.00 \\
Q_{D G_{45}}=161.72\end{array}$ & $\begin{array}{l}\mathrm{P}_{\mathrm{DG}_{45}}=490.07 \\
\mathrm{Q}_{\mathrm{DG}_{45}}=161.09\end{array}$ & $P_{D G_{46}}=484.28$ & $\begin{array}{l}P_{D_{442}}=490.07 \\
\mathrm{QDG}_{42}=161.09\end{array}$ & $\begin{array}{l}P_{D_{G_{13}}}=488.01 \\
Q_{D_{13}}=160.41\end{array}$ \\
\hline $\mathrm{QC}_{15}=225.0$ & - & $\mathrm{QC}_{15}=125.0$ & $\mathrm{QC}_{13}=300.0$ & - & $Q_{26}=200.00$ \\
\hline $\mathrm{QC}_{16}=150.0$ & - & $\mathrm{QC}_{16}=25.00$ & $\mathrm{QC}_{48}=300.0$ & - & $\mathrm{QC}_{41}=125.00$ \\
\hline $\mathrm{QC}_{14}=300.0$ & - & $\mathrm{QC}_{14}=300.0$ & $\mathrm{QC}_{41}=300.0$ & - & $\mathrm{QC}_{11}=250 . .00$ \\
\hline
\end{tabular}

Table 4 Optimum sizing of DGs and shunt capacitors for 69-bus system

\begin{tabular}{|c|c|c|c|c|c|}
\hline \multicolumn{3}{|c|}{ Sensitivity analysis [22] } & \multicolumn{3}{|c|}{ Simultaneous optimization-based method } \\
\hline $\begin{array}{l}\text { With upf DGs } \\
\text { and shunt } \\
\text { capacitors }\end{array}$ & $\begin{array}{l}\text { With } 0.95 \text { lag pf } \\
\text { DGs only }\end{array}$ & $\begin{array}{l}\text { With lag pf } \\
\text { DGs and shunt } \\
\text { capacitors }\end{array}$ & $\begin{array}{l}\text { With upf DGs } \\
\text { and shunt } \\
\text { capacitors }\end{array}$ & $\begin{array}{l}\text { With } 0.95 \text { lag pf } \\
\text { DGs only }\end{array}$ & $\begin{array}{l}\text { With lag } 0.95 \mathrm{pf} \\
\text { DGs and shunt } \\
\text { capacitors }\end{array}$ \\
\hline$P_{\mathrm{DG}_{65}}=724.62$ & $\begin{array}{l}P_{\mathrm{DG}_{16}}=760.4 \\
\mathrm{Q}_{\mathrm{DG}_{16}}=249.94\end{array}$ & $\begin{array}{l}P_{\mathrm{DG}_{65}}=736.54 \\
\mathrm{Q}_{\mathrm{DG}_{65}}=242.10\end{array}$ & $P_{\mathrm{DG}_{60}}=718.65$ & $\begin{array}{l}P_{\mathrm{DG}_{63}}=757.42 \\
\mathrm{Q}_{\mathrm{DG}_{63}}=248.96\end{array}$ & $\begin{array}{l}P_{\mathrm{DG}_{64}}=760.40 \\
\mathrm{Q}_{\mathrm{DG}_{64}}=249.94\end{array}$ \\
\hline$P_{\mathrm{DG}_{64}}=760.40$ & $\begin{array}{l}P_{D_{G_{15}}}=760.4 \\
Q_{D_{15}}=249.94\end{array}$ & $\begin{array}{l}P_{D_{G_{64}}}=757.42 \\
Q_{D G_{64}}=248.96\end{array}$ & $P_{\mathrm{DG}_{40}}=757.42$ & $\begin{array}{l}P_{D_{G_{68}}}=754.44 \\
Q_{D G_{68}}=247.98\end{array}$ & $\begin{array}{l}P_{D_{G_{68}}}=733.56 \\
Q_{D G_{68}}=241.12\end{array}$ \\
\hline$P_{\mathrm{DG}_{63}}=760.40$ & $\begin{array}{l}P_{\mathrm{DG}_{45}}=760.4 \\
\mathrm{QDG}_{45}=249.94\end{array}$ & $\begin{array}{l}P_{\mathrm{DG}_{63}}=748.47 \\
\mathrm{QDG}_{63}=246.02\end{array}$ & $P_{\mathrm{DG}_{64}}=757.42$ & $\begin{array}{l}P_{\mathrm{DG}_{61}}=760.4 \\
\mathrm{QDG}_{61}=249.94\end{array}$ & $\begin{array}{l}P_{\mathrm{DG}_{62}}=745.49 \\
\mathrm{QDG}_{62}=245.04\end{array}$ \\
\hline $\mathrm{QC}_{65}=525.00$ & - & $Q_{65}=150.00$ & $\mathrm{QC}_{18}=525.00$ & - & $\mathrm{QC}_{61}=475.00$ \\
\hline $\mathrm{QC}_{64}=525.00$ & - & $Q_{64}=200.00$ & $\mathrm{QC}_{58}=500.00$ & - & $Q_{56}=450.00$ \\
\hline $\mathrm{QC}_{63}=525.00$ & - & $\mathrm{QC}_{63}=500.00$ & $\mathrm{QC}_{61}=525.00$ & - & $\mathrm{QC}_{48}=450.00$ \\
\hline
\end{tabular}

From Tables 3 and 4, it can be seen that the real power supply sizing of DGs units is little high with simultaneous optimization method compared to sensitivity analysis method. The reactive power supply in the case of 0.95 lag power factor DGs is very less compared to the other two cases considered using both the methods. In the case of 0.95 lag pf DG units in combination with shunt capacitors the reactive power is partly supplied by the DG units and the remaining necessary reactive power is supplied by shunt capacitors.

The distribution system performance is shown in Tables 5 and 6 for two distribution networks for the two cases considered with the proposed methodology.

From Table 5 it can be seen that the substation power supply with upf DGs and shunt capacitors is $1350.87 \mathrm{~kW}$ which is $50 \%$ of base value $2592.56 \mathrm{~kW}$ of 51 -bus distribution network with sensitivity analysis approach. Similarly in the case of $0.95 \mathrm{lag}$ pf DGs and with the combination of 0.95 lag pf DGs and shunt capacitors the substation power supply is $48.42 \%$ and $52.51 \%$ of the base case, respectively. In the case of simultaneous optimization approach the substation power supply values are $39.84 \%$ in the case of upf DGs and shunt capacitors, 39.98\% in the case of 0.95 lag pf DGs and $39.72 \%$ in the case of 0.95 pf DGs and shunt capacitors, respectively, for 51-node 
Table 5 Performance of 51-node distribution system

\begin{tabular}{|c|c|c|c|c|c|c|}
\hline \multirow{2}{*}{$\begin{array}{l}\text { 51-node } \\
\text { distribution } \\
\text { system }\end{array}$} & \multicolumn{3}{|c|}{ Sensitivity analysis [22] } & \multicolumn{3}{|c|}{$\begin{array}{l}\text { Simultaneous optimization-based } \\
\text { method }\end{array}$} \\
\hline & $\begin{array}{l}\text { upf DGs } \\
\text { and shunt } \\
\text { capacitors }\end{array}$ & $\begin{array}{l}0.95 \text { lag pf } \\
\text { DGs only }\end{array}$ & $\begin{array}{l}0.95 \text { lag } \\
\text { pf DGs } \\
\text { and shunt } \\
\text { capacitors }\end{array}$ & $\begin{array}{l}\text { upf DGs } \\
\text { and shunt } \\
\text { capacitors }\end{array}$ & $\begin{array}{l}0.95 \text { lag pf } \\
\text { DGs Only }\end{array}$ & $\begin{array}{l}0.95 \text { lag } \\
\text { pf DGs } \\
\text { and shunt } \\
\text { capacitors }\end{array}$ \\
\hline $\begin{array}{l}\text { S/S active } \\
\text { power (kW) }\end{array}$ & 1350.87 & 1255.37 & 1361.46 & 1032.98 & 1036.65 & 1029.87 \\
\hline $\begin{array}{l}\mathrm{S} / \mathrm{S} \text { reactive } \\
\text { power (KVAR) }\end{array}$ & 930.53 & 1187.65 & 768.23 & 687.17 & 1112.82 & 529.57 \\
\hline $\begin{array}{l}\text { Real power } \\
\text { loss (kW) }\end{array}$ & 72.53 & 65.78 & 67.69 & 32.47 & 38.07 & 34.29 \\
\hline $\begin{array}{l}\text { Reactive } \\
\text { power loss } \\
\text { (kVAR) }\end{array}$ & 36.53 & 37.22 & 33.55 & 18.17 & 25.17 & 17.91 \\
\hline $\begin{array}{l}\text { Voltage }(V(p . u)) \\
\quad(\text { minimum })\end{array}$ & $0.9664\left(V_{39}\right)$ & $0.9642\left(V_{39}\right)$ & $0.9684\left(V_{39}\right)$ & $0.9733\left(V_{39}\right)$ & $0.9677\left(V_{39}\right)$ & $0.9743\left(V_{51}\right)$ \\
\hline $\begin{array}{l}\text { Voltage stabil- } \\
\text { ity index }\end{array}$ & 0.0363 & 0.364 & 0.0363 & 0.0361 & 0.0363 & 0.0361 \\
\hline
\end{tabular}

Table 6 Performance of 69-node distribution system

\begin{tabular}{|c|c|c|c|c|c|c|}
\hline \multirow{2}{*}{$\begin{array}{l}\text { 69-node } \\
\text { distribution } \\
\text { system }\end{array}$} & \multicolumn{3}{|c|}{ Sensitivity analysis [22] } & \multicolumn{3}{|c|}{$\begin{array}{l}\text { Simultaneous optimization-based } \\
\text { method }\end{array}$} \\
\hline & $\begin{array}{l}\text { upf DGs } \\
\text { and shunt } \\
\text { capacitors }\end{array}$ & $\begin{array}{l}0.95 \text { lag pf } \\
\text { DGs only }\end{array}$ & $\begin{array}{l}0.95 \text { lag } \\
\text { pf DGs } \\
\text { and shunt } \\
\text { capacitors }\end{array}$ & $\begin{array}{l}\text { upf DGs } \\
\text { and shunt } \\
\text { capacitors }\end{array}$ & $\begin{array}{l}0.95 \text { lag pf } \\
\text { DGs only }\end{array}$ & $\begin{array}{l}0.95 \text { lag } \\
\text { pf DGs } \\
\text { and shunt } \\
\text { capacitors }\end{array}$ \\
\hline $\begin{array}{l}\text { S/S active } \\
\text { power (kW) }\end{array}$ & 1607.72 & 1576.86 & 1609.18 & 1584.90 & 1563.62 & 1577.89 \\
\hline $\begin{array}{l}\mathrm{S} / \mathrm{S} \text { reactive } \\
\text { power (KVAR) }\end{array}$ & 1146.58 & 1974.11 & 1133.68 & 1131.90 & 1966.81 & 594.04 \\
\hline $\begin{array}{l}\text { Real power } \\
\text { loss (kW) }\end{array}$ & 50.95 & 55.87 & 49.42 & 19.18 & 33.69 & 15.15 \\
\hline $\begin{array}{l}\text { Reactive } \\
\text { power loss } \\
\text { (kVAR) }\end{array}$ & 26.98 & 29.34 & 26.17 & 12.30 & 19.09 & 10.55 \\
\hline $\begin{array}{l}\text { Voltage }(\mathrm{V}(\mathrm{p} . \mathrm{u})) \\
\quad(\text { minimum })\end{array}$ & $0.9756\left(V_{27}\right)$ & $0.9732\left(V_{27}\right)$ & $0.9756\left(V_{27}\right)$ & $0.9859\left(V_{65}\right)$ & $0.9810\left(V_{65}\right)$ & $0.9850\left(V_{27}\right)$ \\
\hline $\begin{array}{l}\text { Voltage stabil- } \\
\text { ity index }\end{array}$ & 0.0196 & 0.0197 & 0.0196 & 0.0154 & 0.0156 & 0.0153 \\
\hline
\end{tabular}

distribution system. In case of 69-bus distribution network with sensitivity analysis approach the substation power supply values are $39.92 \%, 39.15 \%$ and $39.95 \%$ of base case, respectively, for the three cases considered.

In the case of simultaneous optimization approach for 69-bus system from Table 6, the values are $39.35 \%, 38.83 \%$ and $39.18 \%$, respectively, for case- 1 , case- 2 and case- 3 . The present work focused at minimizing the substation power supply to $40 \%$ of the base vale.

Hence from the above discussion it can be noted that with simultaneous optimization the substation power supply is reduced to $40 \%$ of the base value approach for 
both the distribution networks considered for both 51-bus and 69-bus distribution networks. It can also be observed that the objective of substation power supply can be achieved in all the three cases considered with simultaneous optimization approach.

From Tables 5 and 6 , the reactive power at the substation using sensitivity analysis approach for 51 -node distribution system is $55.36 \%, 70.66 \%$ and $45.71 \%$ of the base values, and using simultaneous optimization method $40.89 \%, 66.20 \%$ and $31.51 \%$, respectively, for the three cases considered. The reactive power at the substation using sensitivity analysis approach for 69 -node distribution system is $41 \%, 70.59 \%$ and $40.54 \%$ of the base values, and using simultaneous optimization method $40.47 \%$, $70.32 \%$ and $21.24 \%$, respectively, for the three cases. This work aims to reduce the substation reactive power supply to $40 \%$ of the base value.

From the above discussion it can be observed that the reactive power supply can only be reduced to $70 \%$ of the base value, i.e., considering only 0.95 lag pf DGs using both sensitivity and simultaneous optimization methods. It can also be observed that the reduction of substation power is more in the case of 0.95 lag pf DGs in combination with shunt capacitors compared to other two cases.

From Tables 5 and 6 , the active power and reactive power loss are reduced to below $40 \%$ of the base value and the reduction is much less in the case of 0.95 lag pf DGs in combination with shunt capacitors using simultaneous optimization method compared to other cases. From Tables 5 and 6, it can also be observed that the voltage profile improvement and sensitivity index are improved much better in the case of 0.95 lag pf DGs and shunt capacitors case using simultaneous optimization method in comparison with other cases.

Finally, the proposed fuzzy GA-based sensitivity analysis and simultaneous optimization techniques are compared with GA-based conventional multiobjective approach proposed in [4] and loss sensitivity-based methodology proposed in [9].

The performance comparison for 51- and 69-node networks for the fuzzy GA-based sensitivity analysis [22] and proposed simultaneous optimization techniques for the case of 0.95 lag pf DGs and shunt capacitors with the methodologies proposed in [4] and [9] are shown in Tables 7 and 8, respectively.

From Tables 7 and 8, it can be said that the performance of the distribution system for the two examples considered is much better in the case of fuzzy GA-based simultaneous optimization technique compared to other cases considered.

The comparison of branch current capacity among the GA-based multiobjective method [4], loss sensitivity-based method and sensitivity analysis [22] and proposed fuzzy GA-based simultaneous optimization methods is shown in Figs. 6 and 7, respectively.

From Figs. 6 and 7 it can be observed that the branch current capacity improvement with sensitivity analysis-based methods is much less compared with simultaneous optimization techniques and the improvement is much better in the case of proposed fuzzy GA-based simultaneous optimization technique with the incorporation of 0.95 lpf DGs and SCs for both 51- and 69-node networks. 
Table 7 Performance comparison for 51-node distribution system

\begin{tabular}{|c|c|c|c|c|}
\hline $\begin{array}{l}\text { 51-node distribution } \\
\text { system }\end{array}$ & $\begin{array}{l}\text { Methodology } \\
\text { proposed } \\
\text { in [4] }\end{array}$ & $\begin{array}{l}\text { Methodology } \\
\text { proposed } \\
\text { in [9] }\end{array}$ & $\begin{array}{l}\text { Sensitivity analysis } \\
\text { method [22] (0.95 lag } \\
\text { pf DGs and SCs) }\end{array}$ & $\begin{array}{l}\text { Proposed simultaneous } \\
\text { optimization method } \\
\text { (0.95 lag pf DGs } \\
\text { and SCs) }\end{array}$ \\
\hline $\mathrm{S} / \mathrm{S}$ active power $(\mathrm{kW})$ & 1229.92 & 1047.61 & 1361.46 & 1029.87 \\
\hline $\begin{array}{l}\text { S/S reactive power } \\
\text { (kVAR) }\end{array}$ & 791.45 & 611.55 & 768.23 & 529.57 \\
\hline Real power loss (kW) & 36.10 & 59.59 & 67.69 & 34.29 \\
\hline $\begin{array}{l}\text { Reactive power loss } \\
\text { (kVAR) }\end{array}$ & 22.45 & 63.61 & 33.55 & 17.91 \\
\hline $\begin{array}{l}\text { Voltage }(V(p . u))(\text { mini- } \\
\text { mum) }\end{array}$ & $0.9711\left(V_{51}\right)$ & $0.9615\left(V_{45}\right)$ & $0.9684\left(V_{39}\right)$ & $0.9743\left(V_{51}\right)$ \\
\hline Voltage stability index & 0.0362 & 0.0362 & 0.0363 & 0.0361 \\
\hline
\end{tabular}

Table 8 Performance comparison for 69-node distribution system

\begin{tabular}{|c|c|c|c|c|}
\hline $\begin{array}{l}69 \text {-node distribution } \\
\text { system }\end{array}$ & $\begin{array}{l}\text { Methodology } \\
\text { proposed } \\
\text { in [4] }\end{array}$ & $\begin{array}{l}\text { Methodology } \\
\text { proposed } \\
\text { in [9] }\end{array}$ & $\begin{array}{l}\text { Sensitivity analysis } \\
\text { method [22] (0.95 lag } \\
\text { pf DGs and SCs) }\end{array}$ & $\begin{array}{l}\text { Proposed simultaneous } \\
\text { optimization method } \\
\text { ( } 0.95 \text { lag pf DGs } \\
\text { and SCs) }\end{array}$ \\
\hline $\mathrm{S} / \mathrm{S}$ active power $(\mathrm{kW})$ & 2213.03 & 2003.64 & 1609.18 & 1577.89 \\
\hline $\begin{array}{l}\text { S/S reactive power } \\
\quad(\mathrm{kVAR})\end{array}$ & 1411.55 & 1435.26 & 1133.68 & 594.04 \\
\hline Real power loss (kW) & 36.09 & 23.42 & 49.42 & 15.15 \\
\hline $\begin{array}{l}\text { Reactive power loss } \\
\text { (kVAR) }\end{array}$ & 18.81 & 14.54 & 26.17 & 10.55 \\
\hline $\begin{array}{l}\text { Voltage }(V(p . u))(\text { mini- } \\
\text { mum) }\end{array}$ & $0.9758\left(V_{27}\right)$ & $0.9724\left(V_{27}\right)$ & $0.9756\left(V_{27}\right)$ & $0.9850\left(V_{27}\right)$ \\
\hline Voltage stability index & 0.0172 & 0.0197 & 0.0196 & 0.0153 \\
\hline
\end{tabular}

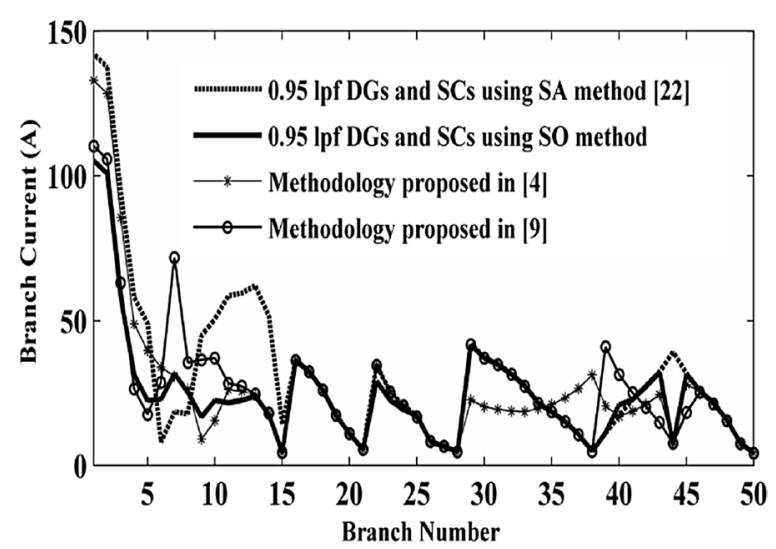

Fig. 6 Branch current capacity comparison with methods [4] and [9] for 51-node network 


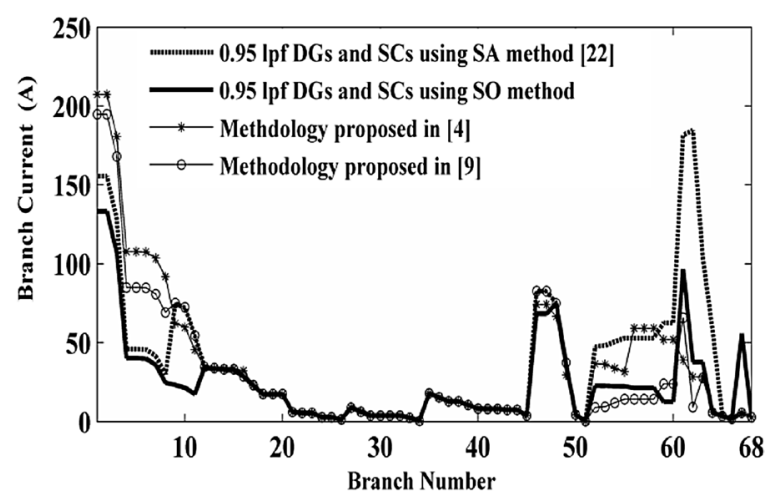

Fig. 7 Branch current capacity comparison with methods [4] and [9] for 69-node network

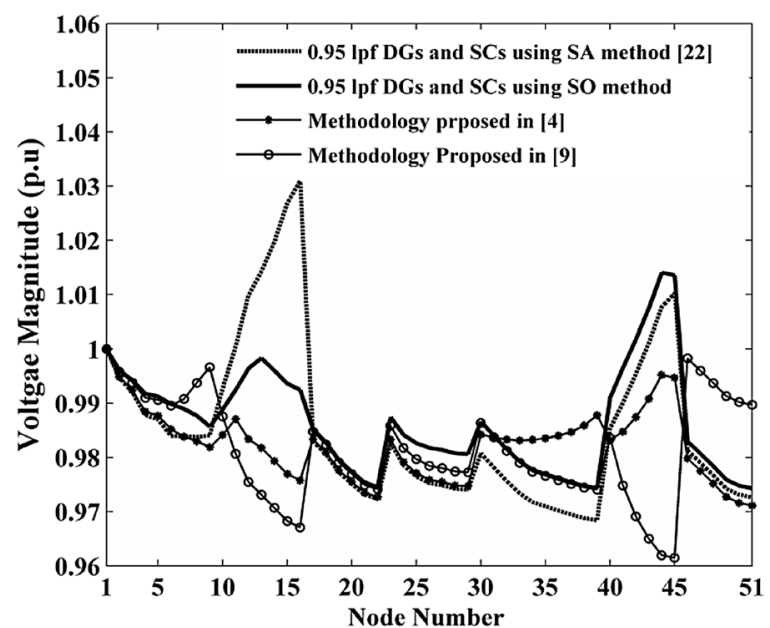

Fig. 8 Voltage profile comparison with methods [4] and [9] for 51-node network

The voltage profile comparison among methodologies $[4,9,22]$ and proposed method is shown in Figs. 8 and 9.

From Figs. 8 and 9, it can be found that the voltage profile improvement is much better in the case of proposed fuzzy GA-based simultaneous optimization technique with $0.95 \mathrm{lpf}$ DGs and SCs for both 51- and 69-node distribution networks. Figure 10 shows the convergence plots obtained using the proposed fuzzy GA-based multiobjective approach.

From the above figure it can be observed that the with the proposed fuzzy GA approach all the six fuzzy objectives defined for improving the performance of the distribution system are completely achieved. The computation time with the proposed fuzzy GA method for obtaining the optimum solution for 51-bus system is $14.235 \mathrm{~s}$ and for 69-bus system is $34.368 \mathrm{~s}$. 


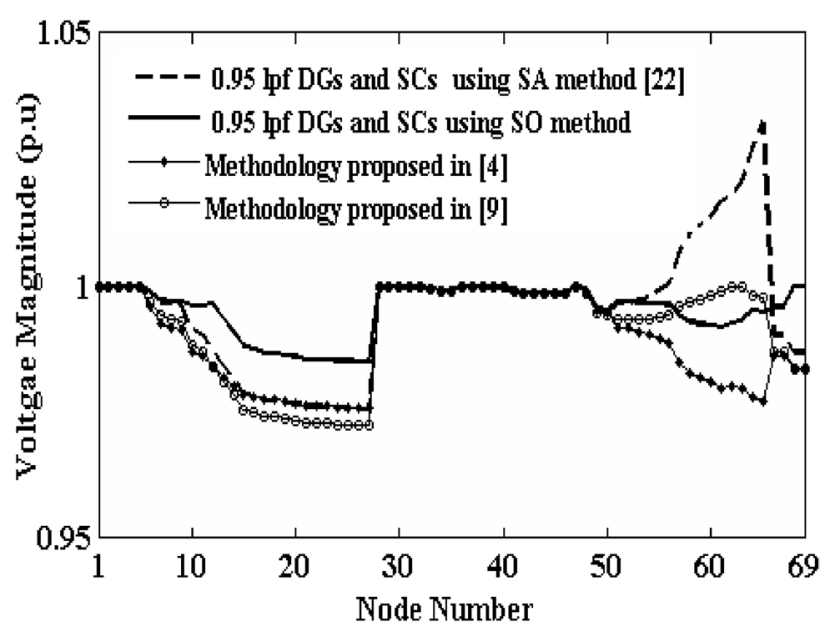

Fig. 9 Voltage profile comparison with methods [4] and [9] for 69-node network
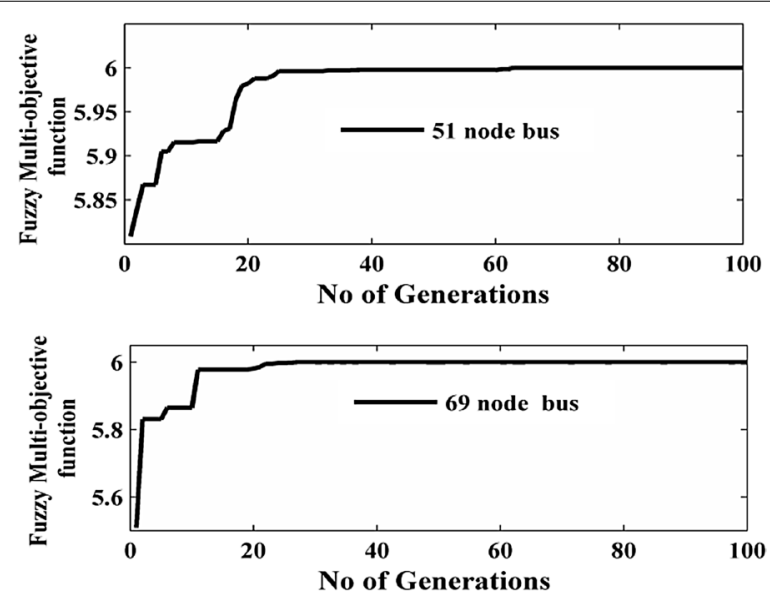

Fig. 10 Convergence characteristics with proposed fuzzy GA methodology for 51- and 69-node systems

\section{Conclusions}

In this work fuzzy GA-based multiobjective methodology is proposed for simultaneous placement of DGs and shunt capacitors in distribution systems for performance improvement of distribution system. The objectives considered in the present work aimed at reduction of real and reactive power supplies at substation, minimizing the real power loss, keeping the voltage magnitude in between minimum and maximum specified voltage limit at all the node voltages of the distribution system, improving branch current capacity, and improvement of voltage stability of the network. The distribution system performance is analyzed considering the combination of shunt capacitors with both upf DG units and lagging pf DG units. From the result analysis it can be said that the distribution system performance is much better in the case of simultaneous optimization technique compared to sensitivity analysis-based optimal placement of DGs and shunt capacitors. The active and reactive power supply needs of the distributions system can be effectively met with combination of shunt capacitors with lagging pf DGs 
compared to all other cases and the reactive power needs cannot be met with considering only lagging pf DGs incorporation. The shunt capacitor sizing can be reduced effectively with the combination of lagging pf DGs and shunt capacitors compared to the combination of upf DGs and shunt capacitors. The real power loss reduction, reactive power loss reduction, voltage profile improvement, branch current capacity improvement and voltage stability improvement can be achieved much better with the combination of lagging pf DGs and shunt capacitors using proposed fuzzy GA-based simultaneous optimization technique. From the simulation results it can also be observed that the performance of the distribution network with proposed fuzzy genetic algorithm-based simultaneous optimization methodology is much better compared with GA-based conventional multiobjective approach and loss sensitivity-based methods.

\begin{abstract}
Abbreviations
$\mathrm{BCl}_{i}$ : branch current carrying ability index $\left(B C l_{j}\right) ; l_{i}$ : magnitude of ith branch current; $\mid C_{i}$ r rating of $i$ th branch current; $F$ : fuzzy multiobjective function; NB: total no of nodes of distribution system; Ploss: active power loss due to active power penetration by upf DG/reactive power injection by capacitor at node $k$; PLI: active power loss index; $\mathrm{PLI}$ min: minimum value of active power loss index; $\mathrm{PLI}_{\max }$ : maximum value of active power loss index; $\mathrm{Ploss}^{\mathrm{DG}}$ : active power loss with installation of DGs and shunt capacitors; Ploss ${ }^{\text {base: }}$ : active power loss without installation of DGs and shunt capacitors; SPSI: S/S real power supply index; SPSI max: maximum value of S/S real power supply index; SPSI $I_{\min }$ : minimum value of S/S real power supply index; SPS DGSC: active power supplied by substation with DGs and shunt capacitors; SPS $^{\text {Base: }}$ : substation active power with base case configuration; SQSI: S/S reactive power supply index; SQS ${ }^{D G S C}$ : reactive power supplied with DGs and shunt capacitors; $S Q S^{B a s e}$ : substation reactive power with base case configuration; $S_{k}$ : sensitivity index of kth node; $P_{n}$ : real power at receiving end node; $Q_{n}$ : reactive power at receiving end node; $x_{m n}$ : reactance of branch ' $m n$ '; $r_{m n}$ : resistance of branch ' $m n^{\prime} ; u_{\min }$ : minimum value of voltage stability index; $u_{\max }$ : maximum value of voltage stability index; $V_{m}$ : sending end node voltage; $u$ : voltage stability index; $\tilde{V}_{m, k}^{\mathrm{DG} / \mathrm{SC}}: m$ th node voltage with installation of DG/capacitor bank

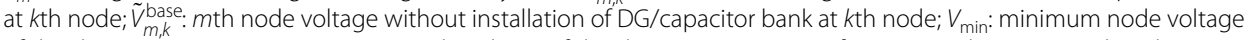
of distribution system; $V_{\max }$ : maximum node voltage of distribution system; $\mu_{\mathrm{sps}}$ : fuzzy $S / S$ real power supply index; $\mu_{\mathrm{sQs}}$ : fuzzy $S / S$ reactive power supply index; $\mu_{P L L}$ : fuzzy active power loss index; $\mu_{B C I T}$ : fuzzy branch current carrying capacity index; $\mu_{V_{i}}$ fuzzy membership function for individual node voltage; $\mu_{V T}$ : fuzzy voltage limit index; $\mu_{\mathrm{u}}$ : fuzzy voltage stability index; $\mathrm{SI}_{n}$ : voltage stability index of $n$th node; $\Delta V_{k}^{\max }$ : highest voltage change in the network by active power penetration by upf $D G /$ reactive power penetration by capacitor at $k$ th node.
\end{abstract}

\title{
Acknowledgements
}

Not applicable.

\section{Authors' contributions}

SRG, the first author has participated with the co-author in the literature survey discussions and in developing and designing the fuzzy membership functions. He developed the fuzzy GA algorithm and the required Matlab source codes for obtaining the optimum sizing and placement of shunt capacitors using proposed fuzzy GA approach. The author has prepared tables, figures and results section and body of the manuscript. DD, The co-author has participated in the literature survey discussions and mainly developed the fuzzy voltage stability index membership function and participated in the design of fuzzy multiobjective function. The author has developed fuzzy GA-based algorithm for obtaining the optimum placement of DGs and shunt capacitors. The author developed content of the "Results and discussion" and "Conclusion" sections. All authors read and approved the final manuscript.

\section{Authors' information}

Srinivasa Rao Gampa received his Ph.D. degree from Indian Institute of Technology Kharagpur, India, in 2016. Currently, he is working as professor in the Gudlavalleru Engineering College, Gudlavalleru, Andhra Pradesh, India. His research interests are electric power distribution systems, distributed generation, renewable energy, and microgrids.

Debapriya Das received his Ph.D. degree from Indian Institute of Technology Delhi, India, in 1992. Currently, he is professor at the Indian Institute of Technology Kharagpur, Kharagpur, West Bengal, India. His research interests are electric power distribution system, power system operation and control, and microgrid operation.

\section{Funding}

The authors have not received funding from any organization related to this work.

\section{Availability of data and materials}

All data generated or analyzed during this study are included in this manuscript.

\section{Competing interests}

The authors declare that they have no competing interests related to this work.

\section{Author details}

${ }^{1}$ Department of Electrical and Electronics Engineering, Gudlavalleru Engineering College, Gudlavalleru, Andhra Pradesh 521356, India. ${ }^{2}$ Department of Electrical Engineering, I.IT Kharagpur, Kharagpur, West Bengal 721302, India. 
Received: 20 August 2019 Accepted: 15 October 2019

Published online: 27 November 2019

\section{References}

1. El-Khattam W, Salama MMA (2004) Distributed generation technologies, definitions and benefits. Electric Power Syst Res 71(2):119-128

2. Ganguly S, Sahoo NC, Das D (2010) A novel multi-objective PSO for electrical distribution system planning incorporating distributed generation. Energy Syst 1(3):291-337

3. Szuvovivski I, Fernandes TSP, Aoki AR (2012) Simultaneous allocation of capacitors and voltage regulators at distribution networks using Genetic Algorithms and Optimal Power Flow. Int J Electr Power Energy Syst 40(1):62-69

4. Kalantari M, Kazemi A (2011) Placement of distributed generation unit and capacitor allocation in distribution systems using genetic algorithm. In: Proceedings of 10th international conference on environment and electrical engineering, Rome, 1-5

5. Griffin T, Tomsovic K, Secrest D, Law A (2000) Placement of dispersed generation systems for reduced losses. In: Proceedings of 33rd Annual Hawaii International Conference on System Sciences

6. Sajjadi SM, Haghifam M, Salehi J (2013) Simultaneous placement of distributed generation and capacitors in distribution networks considering voltage stability index. Int J Electr Power Energy Syst 46:366-375

7. Moradi MH, Zeinalzadeh A, Mohammadi Y, Abedini M (2013) An efficient hybrid method for solving the optimal sitting and sizing problem of DG and shunt capacitor banks simultaneously based on imperialist competitive algorithm and genetic algorithm. Int J Electr Power Energy Syst 54:101-111

8. Jain N, Singh SN, Srivastava SC (2014) PSO based placement of multiple wind DGs and capacitors utilizing probabilistic load flow model. Swarm Evol Comput 19:15-24

9. Naik SG, Khatod DK, Sharma MP (2013) Optimal allocation of combined DG and capacitor for real power loss minimization in distribution networks. Int J Electr Power Energy Syst 53:967-973

10. Gampa SR, Das D (2015) Optimum placement and sizing of DGs considering average hourly variations of load. Int J Electr Power Energy Syst 66:25-40

11. Zeinalzadeh A, Mohammadi Y, Moradi MH (2015) Optimal multi objective placement and sizing of multiple DGs and shunt capacitor banks simultaneously considering load uncertainty via MOPSO approach. Int J Electr Power Energy Syst 67:336-349

12. Kanwar N, Gupta N, Niazi KR, Swarnkar A (2015) Improved meta-heuristic techniques for simultaneous capacitor and DG allocation in radial distribution networks. Int J Electr Power Energy Syst 73:653-664

13. Nasim AK, Ghoshal SP, Ghosh S (2015) Optimal allocation of distributed generation and shunt capacitors for the reduction of total voltage deviation and total line loss in radial distribution systems using binary collective animal behavior optimization algorithm. J Electr Power Comp Syst 43(2):119-133

14. Gampa SR, Das D (2016) Optimum placement of shunt capacitors in a radial distribution system for substation power factor improvement using fuzzy GA method. Int J Electr Power Energy Syst 77:314-326

15. Tah A, Das D (2016) Novel analytical method for the placement and sizing of distributed generation unit on distribution networks with and without considering P and PQV buses. Int J Electr Power Energy Syst 78:401-413

16. Ghaffarzadeh N, Sadeghi H (2016) A new efficient BBO based method for simultaneous placement of inverter-based DG units and capacitors considering harmonic limits. Int J Electr Power Energy Syst 80:37-45

17. Khodabakhshian A, Andishgar MH (2016) Simultaneous placement and sizing of DGs and shunt capacitors in distribution systems by using IMDE algorithm. Int J Electr Power Energy Syst 82:599-607

18. Rahmani-andebili M (2016) Simultaneous placement of DG and capacitor in distribution network. Electric Power Systems Research 131:1-10

19. Kayal P, Chanda CK (2016) Strategic approach for reinforcement of intermittent renewable energy sources and capacitor bank for sustainable electric power distribution system. Int J Electr Power Energy Syst 83:335-351

20. Rahiminejad A, Hosseinian SH, Vahidi B, Shahrooyan S (2016) Simultaneous distributed generation placement, capacitor placement, and reconfiguration using a modified teaching-learning-based optimization algorithm. Electric Power Comp Syst 44(14):1631-1644

21. Kanwar N, Gupta N, Niazi KR, Swarnkar A, Bansal RC (2017) Simultaneous allocation of distributed energy resource using improved particle swarm optimization. Appl Energy 185(2):1684-1693

22. Gampa SR, Das D (2017) Multiobjective Approach for Reconfiguration of Distribution Systems with Distributed Generations. Electric Power Comp Syst 45(15):1678-1690

23. Chakraborty M, Das D (2001) Voltage stability analysis of radial distribution networks. Int J Electr Power Energy Syst 23(2):129-135

24. Zadeh LA (1965) Fuzzy Sets. Inf Control 8:338-353

25. Goldberg DE (1989) Genetic algorithms in search, optimization and learning. Addison-Wesley Longman Publishing Co, Boston

\section{Publisher's Note}

Springer Nature remains neutral with regard to jurisdictional claims in published maps and institutional affiliations. 